\title{
EFFECT OF THE COMBINATION OF ENZYMATIC PREPARATIONS ON THE AQUEOUS EXTRACTION YIELD OF THE OIL FROM THE PULP OF Euterpe oleracea FRUIT
}

\author{
E. de S. Ferreira ${ }^{1}$, H. L. G. Rogez ${ }^{1}$ and C. A. N. P. Herman ${ }^{1 *}$ \\ ${ }^{1}$ Centre for Valorization of Amazonian Bioactive Compounds (CVACBA), Universidade Federal do Pará, Av. Perimetral da Ciência, \\ km 01, s/n, 66.095-780 Belém-PA, Brazil.
}

(Submitted: June 6, 2017 ; Revised: December 11, 2017 ; Accepted: December 19, 2017)

\begin{abstract}
This work aimed to study the effect of the combination of four commercial enzymatic preparations (Celluclast 1.5 L, Viscozyme L, Ultrazym AFP, and Shearzyme $500 \mathrm{~L}$ ) on the aqueous extraction yield of the oil from the pulp of Euterpe oleracea fruit. The enzymatic preparations were tested individually and in combinations of two, three and four, in triplicate. The negative control presented the lowest extraction yield (34.91\%). The tests performed with the isolated enzymatic preparations presented an average increase in the extraction yield of approximately $30 \%$ compared to the negative control, confirming the important role of the enzymes in the extraction process. The tests performed with the combination of more than two enzymatic preparations increased the extraction yield by approximately $90 \%$ compared to the negative control, demonstrating the advantage of using combinations of enzymes. Among the different tests, those performed with the combination of three enzymatic preparations, including the cellulase class-type enzyme, Celluclast $1.5 \mathrm{~L}$, stood out by presenting a high extraction yield $(>65 \%)$ and being statistically equal to the one using all four, which is interesting for the industry due to the reduced cost of the process.

Keywords: Aqueous extraction; Enzyme; Vegetable oil; Açai palm fruit.
\end{abstract}

\section{INTRODUCTION}

Over the last few decades, the population has been achieving higher longevity. Among other factors, this is due to better quality of life, with emphasis on the relationships between the health of people and a healthy diet (Aiello et al., 2016). The bioactive compounds present in food, especially those of vegetable origin, have been a frequent object of research due to their positive health implications (Liu, 2013).

In this context, the fruit of the açai palm tree (Euterpe oleracea Martius), considered in recent years to be one of the new "superfruit", are being extensively studied due to their nutritional characteristics that deliver positive health effects (Schauss, 2010; Heinrich et al., 2011; Yamaguchi et al., 2015). The pulp of $E$. oleracea fruit presents a beneficial combination of lipids ( $\sim 30-50 \%$, on a dry basis (d.b.) of the pulp), significant concentration of dietary fibers $(\sim 20-50 \%$, d.b.) and relevant content of proteins and amino acids $(\sim 5-10 \%$, d.b.).

Regarding bioactive compounds, the pulp of E. oleracea fruit is an interesting source of bioactive compounds such as phenolic compounds (specifically anthocyanins, proanthocyanidins, and other flavonoids), inorganic compounds (especially calcium, sodium and potassium), and other compounds such as sterols, carotenoids and vitamins, mainly A, C and E (Schauss et al., 2006; Bichara and Rogez, 2011).

\footnotetext{
* Corresponding author: christelle@ufpa.br
} 
A recent review presents the main biological activities of the different parts of the E. oleracea species, including roots, leaves, seeds, fruit, and especially the pulp (Yamaguchi et al., 2015). Regarding the pulp of E. oleracea fruit, research is divided into four categories: chemical characterization assays, in vitro assays, in vitro cell-based assays and in vivo studies using animal and/or human models.

Among the activities under study, the high antioxidant activity and the anti-inflammatory effects are the most commonly reported: see, e.g., the in vivo study in rat model of Machado et al. (2016).

Among other therapeutic properties, some authors demonstrate that the pulp of E. oleracea fruit provides protection against age-related neurodegenerative disorders. For example, one can mention the in vitro cell-based assays using mouse brain BV-2 microglial cells of Poulose et al. (2012) or embryonic hippocampal and HT22 hippocampal neurons of Poulose et al. (2014), and the in vivo studies in rat model of Machado et al. (2016) and Poulose et al. (2017).

The pulp of E. oleracea fruit also helps against cardiovascular diseases - see, e.g., the review of Moura and Resende (2016) -, and atherosclerosis - see, e.g., the in vivo studies with ApoE deficient mice of Xie et al. (2011) and rabbits fed with a cholesterol-enriched diet of Feio et al. (2012).

Finally, the pulp of E. oleracea fruit also presents antiproliferative bioactivity on cancer cells, such as mouse urinary bladder cells (see, e.g., Fragoso et al., 2012), rat colon adenocarcinoma cells (see, e.g., Fragoso et al., 2013), human colon adenocarcinoma cells (see, e.g., Pacheco-Palencia et al., 2008b) or human breast cancer cells (see, e.g., Hogan et al., 2010).

It is worth mentioning that other berries, rich in bioactive compounds, specifically anthocyanins, present a similar spectrum of therapeutic properties (Skrovankova et al., 2015). However, the presence of the considerable amount of lipids in the pulp of $E$. oleracea fruit plays an important role in facilitating the absorption of the bioactive compounds by the organism.

Therefore, more recently, some authors have focused on the chemical composition and biological activities of the oil extracted from the pulp of $E$. oleracea fruit. Such oil is stored in the mesocarp of the pulp of E. oleracea fruit, more specifically in the parenchyma of lipid reserve, which is composed of approximately 5 to 6 layers of elongated cells (Lopes, 2015).

The profile of fatty acids is highly similar to that of olive oil, where more than $70 \%$ consist of mono or polyunsaturated fatty acids. Among these fatty acids, oleic acid, palmitic acid and essential fatty acids, e.g., linoleic and linolenic acids, stand out (Schauss et al.,
2006; Pacheco-Palencia et al., 2008a; Nascimento et al., 2008; Batista et al., 2016).

Furthermore, the oil from the pulp of E. oleracea fruit is rich in apolar natural antioxidants. The major phenolic compounds detected up to now are vanillic acid, syringic acid, protocatechuic acid, caffeic acid, ferulic acid, procyanidin dimers and trimers, quercetin and kaempferol rutinoside (Pacheco-Palencia et al., 2008a; Marques et al., 2016). Moreover, the oil from the pulp of E. oleracea fruit is rich in tocopherols mainly $\alpha$ - and $\beta$-tocopherols (Darnet et al., 2011) -; tocotrienols - specifically $\beta$-tocotrienol (Lubrano et al., 1994) -; and phytosterols - such as $\beta$-sitosterol, campesterol, and sigmasterol (Schauss et al., 2006).

One of the first works about the potential applications of the oil from the pulp of E. oleracea fruit is from Plotkin and Balick (1984), who suggest its antidiarrheic action.

Other studies have shown that the ingestion of the pulp of $E$. oleracea fruit promotes a hypocholesterolemic effect, by the improvement of the serum fatty acid profile, probably due to the fatty acid profile of the oil from the pulp of E. oleracea fruit (Souza et al., 2012).

In reference to the oil from the pulp of E. oleracea fruit, in vitro assays show antimicrobial activity against some bacteria associated with a host of human diseases (see, e.g., Filho and Pereira, 2012). Other in vitro cell-based assays indicate antiproliferative bioactivity on human colon adenocarcinoma cells (see, e.g., Pacheco-Palencia et al., 2008b).

The oral administration of the oil from the pulp of E. oleracea fruit in an in vivo study in rat model demonstrates anti-inflammatory and antinociceptive activities (see, e.g., Favacho et al., 2011) and a beneficial effect on dyslipidemia (see, e.g., Souza et al., 2017).

The topical application of the oil from the pulp of $E$. oleracea fruit in nanoemulsion in in vitro cellbased assays using melanoma cell lines and in vivo studies in mice reveals its potential use as an effective photosensitizer for photodynamic therapy to treat melanoma (see, e.g., Monge-Fuentes et al., 2017).

To date, there is no evidence of genotoxicity of the oil from the pulp of E. oleracea fruit, as reported by some recent research work. As examples, see the in vivo essay in rat model using mammalian cells (leukocytes, liver, bone marrow and testicular cells) of Marques et al. (2016), and the in vitro cell-based assays using human lymphocytes (Maistro et al., 2013) and human hepatoma cell lines (Marques et al., 2017).

Due to these numerous characteristics, the oil from the pulp of E. oleracea fruit is very interesting for the food, cosmetic and pharmaceutical industries (PachecoPalencia et al., 2008a; Pacheco-Palencia et al., 2008b; Heinrich et al., 2011; Yamaguchi et al., 2015). 
As observed, the study and the valorization of the oil from the pulp of E. oleracea fruit is quite recent (>2010) and, up to now, most of the works related to such oil focused on the biological applications and not on the extraction process, useful for manufacturers.

To the best of our knowledge, there is no technology with technical-economic optimization for extracting the oil from the pulp of E. oleracea fruit, relying on the conventional physicochemical methods used at the commercial scale (Yamaguchi et al., 2015). These methods usually employ organic solvents, mainly $n$-hexane, hydraulic press and supercritical $\mathrm{CO}_{2}$ (Batista et al., 2016). Although giving a good extraction yield, they are costly and of difficult manipulation on an industrial scale. In the case of the petroleum solvents, they can also lead to unfavorable economic, safety, and environmental impacts (Rosenthal et al., 1996; Sicaire et al., 2015).

In this context, the search for bio-based solvents or "green" additives has become a major area of interest by scientists in academia and in industry. Nascimento et al. (2008) were the first who reported that the enzymatic aqueous extraction (EAE) process could be an alternative process for the extraction of the oil from the pulp of E. oleracea fruit.

The EAE process of fat and oil consists of an extraction process realized in aqueous medium using enzymes selected for their ability to completely hydrolyze the membrane and the wall of the vegetable cell and release the oil contained inside it (Domínguez et al., 1994; Ricochon and Muniglia, 2010). In comparison to the conventional extraction processes, the use of an aqueous medium is much safer, environmentally friendly and more economical. Moreover, it may contribute to a superior quality of the extracted oil (Yusoff et al., 2015). The main limitations for the application of the EAE process on industrial scale are the cost and the availability of the enzymes, as well as the time and cost of the downstream processes. Eventually, the EAE process allows for the simultaneous extraction of oil and its bioactive compounds, e.g., vitamins, phenolic compounds, carotenoids (Yusoff et al., 2015).

The cell wall is composed of polysaccharides, i.e., cellulose, hemicellulose, pectin, lignin, and proteins. Therefore, for an efficient release of the oil enclosed in the plant cell, one has to use a combination of enzymes specifically designated to break down these different molecules (Rosenthal et al., 1996). The main enzymes of interest in the EAE process of vegetable oil are those of the classes E.C. 3 (hydrolases) and E.C. 4 (lyases). Among the hydrolases, one can cite the enzymes which act on the hydrolysis of ester bonds (subclass 3.1., including hemicellulase and pectinesterase), glycosidic bonds (subclass 3.2., including cellulase and poligalacturonase), or peptidic bonds (subclass 3.3., protease-class type). Among the lyases, the main ones used are the transeliminative enzymes of the subclass 4.2 (e.g., pectin and pectate lyases), which break glycosidic bonds (Ricochon and Muniglia, 2010).

The combination of these classes of enzymes has been successfully employed in recent years in the EAE process of several vegetable oils from raw materials presenting açai-like characteristics in terms of composition (high lipid and protein contents) (see, e.g., the review of Yussof et al., 2015).

On this basis, this work aimed to evaluate the impact of four commercial enzymatic preparations (EP) on the EAE yield of the oil from the pulp of E. oleracea fruit, testing them individually and in combination.

\section{MATERIALS AND METHODS}

\section{Raw Material}

The E. oleracea fruits were collected in Abaetetuba (Pará State, Brazil) in December, 2015 (GPS

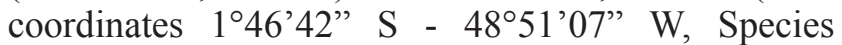
Identification Voucher $\mathrm{n}^{\circ}$ 268513, Instituto Nacional de Pesquisas da Amazonia - INPA). The first stages of the EAE process were: (a) harvest of the fruits; (b) hygienization of the fruits under tap water; (c) softening of the fruits in lukewarm water $\left(40^{\circ} \mathrm{C}\right)$ for 1 hour; (d) manual pulping of the fruits, using sieves, to obtain small pieces of the surrounding pulp of the fruits with mean granulometry of $0.75 \mathrm{~mm}$, commonly known as "decocts"; and (e) storage of the decocts at $-20^{\circ} \mathrm{C}$.

\section{Raw Material Characterization}

The dry matter content of the decocts was determined by the AOCS method (AOCS Cc 7-25) using a stove (Drying and sterilizing stove, SOLAB SL-100, Piracicaba / São Paulo, Brazil) at $105^{\circ} \mathrm{C}$ for 4 hours (AOCS, 1998). The determination of the lipid content of the decocts was performed according to the methodology described by AOCS (AOCS Bd 3-52), using Soxhlet equipment (Soxhlet condenser and extractor, SOLAB SL 145/6, Piracicaba / São Paulo, Brazil) and petroleum ether as the extraction solvent at $60^{\circ} \mathrm{C}$ for 3 hours (AOCS, 1998).

\section{Enzymatic Preparations}

The identification of the commercial EP to be used in this work was done according to the following three criteria: (1) enzymatic action profile according to the cell composition of the pulp of E. oleracea fruit (cellulose, hemicellulose, pectin...); (2) optimal 
Table 1. Main characteristics of the four commercial enzymatic preparations.

\begin{tabular}{clcc}
\hline Commercial name & \multicolumn{1}{c}{ EP composition } & T $\left.{ }^{\circ} \mathbf{C}\right)$ & $\mathbf{p H}$ \\
\hline Celluclast 1.5 L (C) & Cellulase & $50-60$ & $4.5-6.0$ \\
Viscozyme L (V) & Endo 1,3(4) $\beta$-glucanase, xylanase, cellulase, hemicellulase & $40-50$ & $3.3-5.5$ \\
Ultrazym AFP (U) & Pectin lyase, cellulase, polygalacturonase & $35-50$ & $4.0-5.0$ \\
Shearzyme 500 L (S) & Endo 1,4-xylanase & $55-70$ & $5.5-6.0$ \\
\hline
\end{tabular}

enzymatic activity for $\mathrm{pH} \approx 4-5$; and (3) optimal enzymatic activity for temperatures between 30 and $60^{\circ} \mathrm{C}$ (which are the $\mathrm{pH}$ and temperature conditions reached during the EAE process of the oil from the pulp of E. oleracea fruit).

The four commercial EP selected are presented in Table 1. They were produced by Novozymes and purchased from LNF Latino Americana (Bento Gonçalves / Rio Grande do Sul, Brazil). Table 1 presents the commercial name, main composition of the EP, and optimal range of temperature and $\mathrm{pH}$, according to the product data sheet provided by Novozymes.

\section{Process of Enzymatic Aqueous Extraction of the Oil from the Pulp of E. oleracea Fruit}

The EAE process of the oil from the pulp of $E$. oleracea fruit was conducted based on a previous review (Yusoff et al., 2015), and is presented in Figure 1. Each test was performed with $100 \mathrm{~g}$ of decocts from the pulp of E. oleracea fruit. After homogenization and weighing, the decocts were spread in aluminum trays and submitted to a thermal pretreatment with water vapor (Steam cooker, Walita / Philips Jamie Oliver RI9132/01, Barueri / São Paulo, Brazil) until reaching $70^{\circ} \mathrm{C}$, which was maintained for one minute. This procedure aims to denature the enzymes present in the raw material, as well as to allow for the partial destabilization of the lignin.

After this stage, the decocts were transferred to a $600 \mathrm{~mL}$ beaker. In order to facilitate the action of the $\mathrm{EP}$ and the liberation of the oil, $240 \mathrm{~mL}$ of distilled water at room temperature were added, reaching a final water content of the mixture of approximately $85 \%$. The EP were inserted individually, or in combination (according to the test performed), at a concentration of $1 \mathrm{~g}$ of EP to $100 \mathrm{~g}$ of fresh decoct, and the mixture was manually homogenized. The $\mathrm{pH}$ of the aqueous suspension of the decocts at the beginning of the process was approximately 4.7 . The $\mathrm{pH}$ was not adjusted to a fixed value for three reasons: first, because the initial $\mathrm{pH}$ did not present significant differences of values from one enzymatic test to another; second, to avoid the addition of chemicals to the medium; and third, due to the quasi-constant value of the $\mathrm{pH}$ until the end of the EAE process of the oil from the pulp of E. oleracea fruit.

The beakers were sealed with aluminum foil and placed in a shaker (Shaker incubator, SOLAB SL-222,

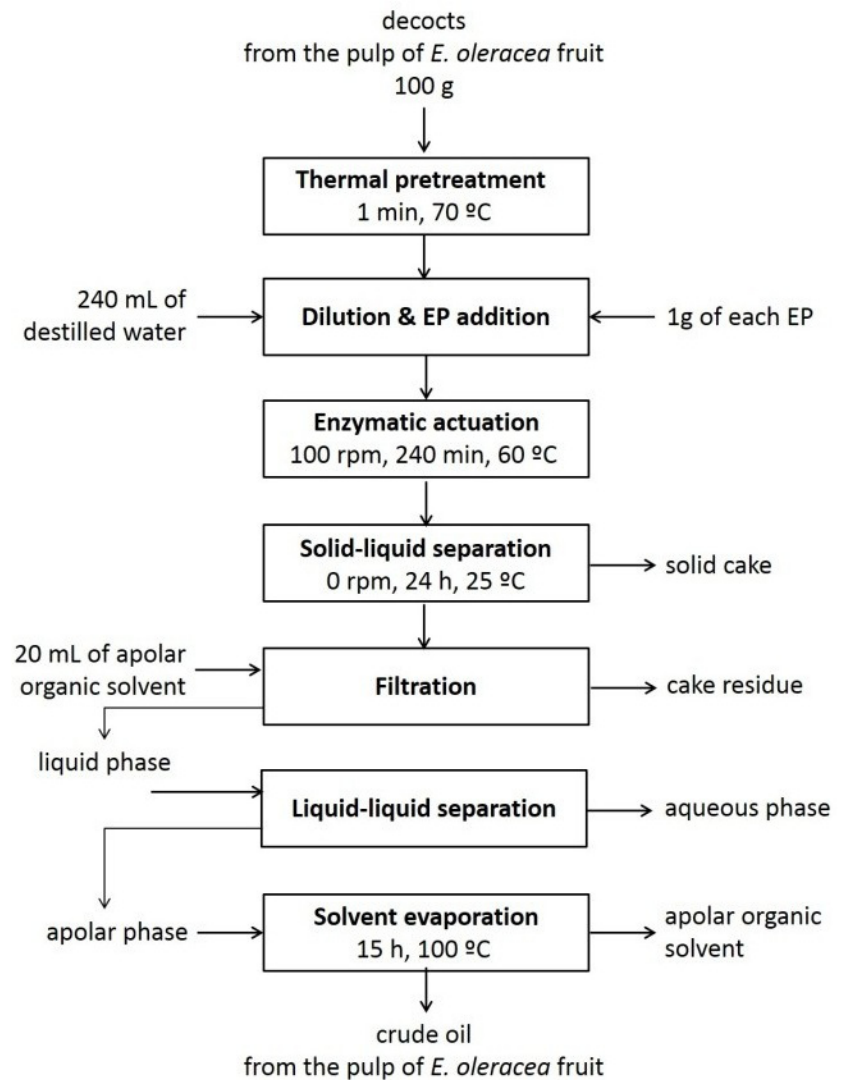

Figure 1. Flow chart of the enzymatic aqueous extraction process of the oil from the pulp of $E$. oleracea fruit.

Piracicaba / São Paulo, Brazil) for $240 \mathrm{~min}$ at $50^{\circ} \mathrm{C}$ with an orbital agitation of $100 \mathrm{rpm}$. Every $30 \mathrm{~min}$, a more vigorous manual agitation was performed for one minute in each beaker to enhance the action of the EP, and to consequently promote a higher release of the oil into the medium. After the incubation, the mixture was quickly cooled in an ice bath until reaching $25^{\circ} \mathrm{C}$.

The beakers rested for approximately $24 \mathrm{~h}$ at room temperature allowing for a natural solid-liquid separation by decantation. The main phases are, from bottom to top: the solid cake (fibrous and high density protein part of the mixture), the aqueous phase (containing some low density proteins) and the lipid phase (consisting of oil droplets dispersed on the surface).

After this period, about $20 \mathrm{~mL}$ of apolar organic solvent ( $n$-hexane) (Dinâmica, Diadema / São Paulo, Brazil) were added to agglomerate all the oil droplets and to favor a complete separation of the lipid phase from the aqueous phase. 
The liquid phase of the mixture (aqueous, lipid and organic phases) was transferred to a clean beaker, from which successive filtrations were made until the elimination of any cake residue. The lipid and apolar organic phases were removed using a micropipette, and transferred to a $100 \mathrm{~mL}$ previously weighed beaker.

These beakers were incubated in a stove (Drying and sterilizing stove, SOLAB SL-100, Piracicaba / São Paulo, Brazil) at $100^{\circ} \mathrm{C}$ for 15 hours, until the complete evaporation of the apolar organic solvent. Then, they were cooled in a desiccator until reaching room temperature. After that, they were weighed (Analytical balance, SHIMADZU UniBloc AUY 220, Barueri / São Paulo, Brazil) to determine the mass of the oil extracted by the EAE process.

The extracted oil was transferred to $1.5 \mathrm{~mL}$ eppendorfs, which were packaged in aluminum foil, identified, and stored at $5^{\circ} \mathrm{C}$ for future analysis.

The calculation of the EAE yield of the oil from the pulp of E. oleracea fruit, expressed in percentage, was done by mass balance, considering the weight of the oil extracted by the EAE process and the total oil present in the initial sample determined by the AOCS official methodology.

\section{Experimental Design}

The experimental design presented a total of 16 tests: 1 negative control test (performed without enzyme: WE), 4 tests using the EP individually, 6 tests using the combination of two EP, 4 tests using the combination of three EP, and 1 test using the combination of all four EP. All tests were realized using an individual concentration of $1 \%$ of each EP. All tests were realized in triplicate.

\section{Statistical Analysis}

The results of the EAE yield were expressed as the average of the triplicate \pm the standard deviation. The results were submitted to the analysis of variance (ANOVA) and LSD Fisher test, with a significance level of 0.05 , using STATISTICA software version 7.0 (Statsoft Inc., Tulsa / Oklahoma, USA).

\section{RESULTS AND DISCUSSION}

Figure 2 presents the results of the EAE yield of the oil from the pulp of E. oleracea fruit, expressed in percentage, for the distinct tests: the negative control (WE), realized without EP, the four isolated EP and the combination of two, three and all four EP.

The negative control test showed an EAE yield of $34.91 \pm 11.81 \%$, which was the lowest EAE yield of all tests performed with one or more EP. This observation

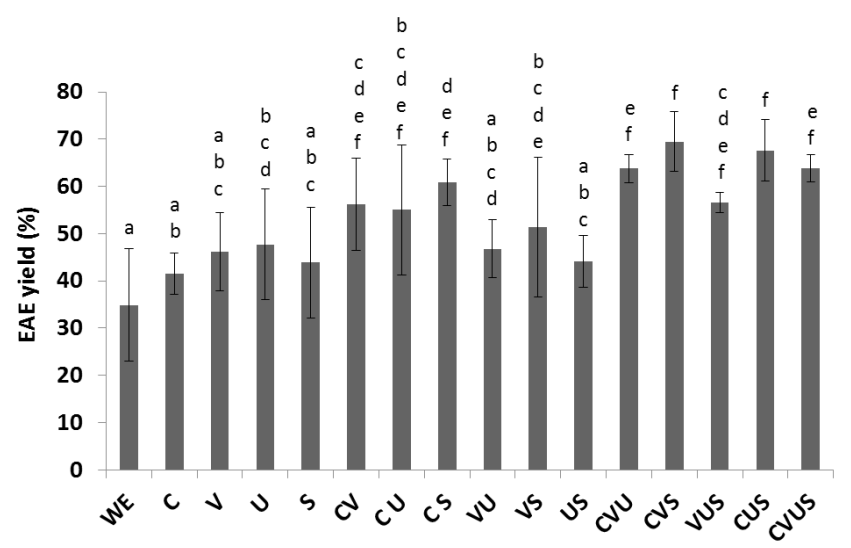

Subtitles: WE: without enzyme; C: Celluclast $1.5 \mathrm{~L}$; V: Viscozyme L; U: Ultrazym AFP and S: Shearzyme $500 \mathrm{~L}$; Significant differences (p value $<$ 0.05 ) between tests are represented by the absence of common lower case letters.

Figure 2. Effect of the commercial enzymatic preparations on the enzymatic aqueous extraction (EAE) yield of the oil from the pulp of E. oleracea fruit.

is similar to the literature for the EAE process of the oil from other vegetables (Yusoff et al., 2015).

More specifically, the four tests performed with the isolated EP showed an average increase of the EAE yield of $28 \%$ compared to the negative control (from $41.52 \pm 4.31 \%$ for Celluclast $1.5 \mathrm{~L}$ to $47.71 \pm 11.72 \%$ for Ultrazym AFP). An increase from $20 \%$ to $50 \%$ in the EAE yield, when compared to the negative control, was also observed by several authors: see, e.g., Abdulkarim et al. (2006) for Moringa oleifera seed, Zhang et al. (2007) for rapeseed, Latif et al. (2008) for canola seed, Latif and Anwar (2009) for sunflower, Rui et al. (2009) for white pitaya seed, Latif and Anwar (2011) for sesame, Gai et al. (2013) for Isatis indigotica seed, Mai et al. (2013) for gac fruit, Tabtabaei and Diosady (2013) for yellow mustard flour, and Jiao et al. (2014) for pumpkin seed.

Using EP presenting different enzymatic compositions (Table 1), the results in Figure 2 showed that there is no significant difference between the EAE yields of the tests using the four EP individually. However, the most highlighted EP was Ultrazym AFP, composed of pectin lyase, cellulase and polygalacturonase (Table 1). Although not showing a significantly different result in relation to the other three EP ( $p$ value $>0.05$ ), it has a significant higher result than the negative control ( $p$ value $<0.05$ ). Similar results were obtained by other authors, who worked with other vegetable raw materials. Zhang et al. (2007) showed a higher yield of the EAE process of the oil from rapeseed using pectinase, followed by cellulase, glucanase and xylanase. Rui et al. (2009) showed a better yield of the EAE process of the oil from white pitaya seeds using EP containing pectinase, followed by protease, cellulase and $\alpha$-amylase. Puangri 
et al. (2005), Latif et al. (2009), Gai et al. (2013), Mai et al. (2013) and Jiao et al. (2014) also showed that pectinase was among the main enzymes that contribute to a higher yield of the EAE process of the oil from papaya seed, sunflower, Isatis indigoga, gac fruit and pumpkin seed, respectively, shortly after cellulase, hemicellulase and/or protease. Interestingly, other works showed that pectinase is among the enzymes with less influence on the EAE process of the oil: see, e.g., Abdulkarim et al. (2006) for Moringa oleifera seed, Latif et al. (2008) for canola seed, Latif and Anwar (2011) for sesame, and Tabtabaei and Diosady (2013) for yellow mustard flour.

The results in Figure 2 demonstrated that the combination of two EP promotes an average increase in the EAE yield of the oil from the pulp of E. oleracea fruit of approximately $17 \%$ compared to the use of isolated EP, probably by acting on different enzymatic sites (Ricochon et al., 2010). Other authors like Zhang et al. (2007), Tabtabaei and Diosady (2013) and Mai et al. (2013) also came to the same conclusion when using a combination of two enzymatic preparations in the EAE process of the oil from rapeseed, yellow mustard flour and gac fruit, respectively.

More specifically, the results pointed out the importance of using Celluclast $1.5 \mathrm{~L}$ together with another EP (Figure 2). The mean EAE yields of the tests "CS", "CV" and "CU" (60.97\%; 56.20\% and $55.02 \%$, respectively) were higher than the other tests ("VU" with $46.81 \%$; "VS" with $51.33 \%$ and "US" with 44.09\%). It is worth mentioning that the EAE yields of the tests "VU" and "US" did not differ statistically from the negative control ( $p$ value $>0.05$ ), which makes them non-advantageous combinations of EP. This can be explained by the absence of a cellulase class-type enzyme, considered the "input enzyme" for the breakdown of the bonds in the plant cell wall, in these combinations (Domínguez et al., 1994).

With the exception of the tests "VU", "VS" and "US", the tests realized with the combination of at least two EP (i.e., two, three and all four) did not differ statistically between them ( $p$ value $>0.05$ ). This suggests that the combination of two EP would be sufficient to disrupt the E. oleracea cell wall and favor the EAE process of the oil. However, it is worth mentioning that, from a practical point of view, the use of more than two EP (i.e., three or all four) strongly facilitated the oil recovery. Other authors also observed that the use of more than two, mainly four or five EP, acting on the different polysaccharides of the vegetable cell wall, greatly facilitated the EAE of the oil at an industrial level: see, e.g., Abdulkarim et al. (2006) for Moringa oleifera seed, Zhang et al. (2007) for rapeseed, Rui et al. (2009) for white pitaya seed, Gai et al. (2013) for Isatis indigotica seed, Mai et al.
(2013) for gac fruit, Tabtabaei and Diosady (2013) for yellow mustard flour, and Jiao et al. (2014) for pumpkin seed.

One can observe in Figure 2 an average increase of the EAE yield of the oil from the pulp of $E$. oleracea fruit of approximately $20 \%$ when using the combination of three EP, compared to the use of the combination of two EP. The results also pointed to the importance of using Celluclast 1.5 L together with other EP. Thus, the only test that showed an inferior EAE yield ( $p$ value $<0.05$ ) was "VUS" $(56.57 \%)$. Among the different tests performed, the three performed with the combination of three EP, including the cellulose class-type enzyme ("CVS", "CUS" and "CVU" with $69.49 \%, 67.62 \%$ and $63.78 \%$, respectively), stood out by presenting a high EAE yield (average of 66.96\%) and for being statistically equal to the one using all four EP $(63.85 \%)$, which is interesting for the industry due to the cost reduction of the process.

Eventually, the combination "CVU" could be selected as the best combination of EP for the EAE process of the oil from the pulp of E. oleracea fruit. This is due to its composition of three complementary EP (including cellulase, hemicellulase and pectinase class-type enzymes), which all act in similar temperature and $\mathrm{pH}$ ranges (Table 1 ).

\section{CONCLUSIONS AND PERSPECTIVE}

Our work focuses on the comparison and the discussion of the effect of individual and combined commercial enzymatic preparations on the aqueous extraction yield of the oil from the pulp of Euterpe oleracea fruit. More specifically, hydrolases and lyase enzymes are investigated. We show that the use of a single enzymatic preparation, at a concentration of $1 \%$, allows an increase of approximately $30 \%$ in the enzymatic aqueous extraction yield, while the combination of at least two enzymatic preparations promotes a two-fold increase compared to the negative control. More specifically, the use of three enzymatic preparations, at an individual concentration of $1 \%$, including cellulase, hemicellulase and pectinase classtype enzymes, is the most relevant combination for maximizing the enzymatic aqueous extraction yield of the oil from the pulp of Euterpe oleracea fruit.

Further studies will be performed in order to determine the optimal combination of the three better enzymatic preparations identified in this work - Celluclast 1.5L, Viscozyme L and Ultrazym AFP using a mixing plane at a total enzymatic concentration of $3 \%$, and the determination of the total optimal enzymatic concentration from both a technical and an economic point of view. 


\section{ACKNOWLEDGMENTS}

The authors are grateful to the Conselho Nacional de Desenvolvimento Científico e Tecnológico (CNPq / Brazil), Coordenação de Aperfeiçoamento de Pessoal de Nivel Superior (CAPES / Brazil), Fundação Amazônia de Amparo a Estudos e Pesquisa do Pará (FAPESPA) and Fundo Amazônia (Brazil) for the financial support and scholarships.

\section{REFERENCES}

Abdulkarim, S.M.; Lai, O.M.; Muhammad, S. K. S.; Long, K.; Ghazali, H. M.. Use of enzymes to enhance oil recovery during aqueous extraction of moringa oleifera seed oil. Journal of Food Lipids, 13, 113-130 (2006).

Aiello, A.; Accardi, G.; Candore, G.; Carruba, G.; Davinelli, S.; Passarino, G.; Scapagnini, G.; Vasto, S.; Caruso, C.. Nutrigerontology: A key for achieving successful ageing and longevity. Immunity \& Ageing, 2016, 13-17 (2016).

Batista, C.C.R.; Oliveira, M.S.; Araújo, M.E.; Rodrigues, A.M.C.; Botelho, J.R.S.; Filho, A.P.S.S.; Machado, N.T.; Junior, R.N.C.. Supercritical $\mathrm{CO}_{2}$ extraction of açai (Euterpe oleracea) berry oil: Global yield, fatty acids, allelopathic activities, and determination of phenolic and anthocyanins total compounds in the residual pulp. Journal of Supercritical Fluids, 107, 364-369 (2016).

Bichara, C.M.G. and Rogez, H.. Chapter 1 - Açai (Euterpe oleracea Martius). In: Postharvest biology and technology of tropical and subtropical fruit: Açai to Citrus. Cambridge: UK Press. pp. 1-26 (2011).

Darnet, S.; Serra, J.L.; Rodrigues, A.M.C.; Silva, L.H.M..Ahigh-performance liquid chromatography method to measure tocopherols in assai pulp (Euterpe oleracea). Food Research International, 44, 2107-2111 (2011).

Domínguez, H.; Núnez, M.J.; Lema, J.M.. Enzymatic pretreatment to enhance oil extraction from fruit and oilseeds: A review. Food Chemistry, 49, 271286 (1994).

Favacho,H.A.S.; Oliveira, B.R.; Santos, K.C.; Medeiroa, B.J.L.; Sousa, P.J.C.; Perazzo, F.F.; Carvalho, J.C.T.. Anti-inflammatory and antinociceptive activities of Euterpe oleracea oil. Brazilian Journal of Pharmacognosy, 21(1), 105-114 (2011).

Feio, C.A.; Izar, M.C.; Ihara, S.S.; Kasmas, S.H.; Martins, C.M.; Feio, M.N.; Maués L.A.; Borges, N.C.; Moreno, R.A.; Póvoa, R.M.; Fonseca, F.A.. Euterpe oleracea (açai) modifies sterol metabolism and attenuates experimentally induced atherosclerosis. Journal of Atherosclerosis and Thrombosis, 19(3), 237-245 (2012).
Filho, A.L.M.; Pereira, M.R.R.. Antimicrobial activity of açai and pupunha oils on the development of Pseudomonas aeruginosa and Staphylococcus aureus. Bioscience Journal, 28(4), 598-603 (2012).

Fragoso, M.F.; Prado, M.G.; Barbosa, L.; Rocha, N.S.; Barbisan, L.F.. Inhibition of mouse urinary bladder carcinogenesis by açai fruit (Euterpe oleracea Martius) intake. Plant Foods for Human Nutrition, 67, 235-241 (2012).

Fragoso, M.F.; Romualdo, R. G.; Ribeiro, D. A.; Barbisan, L.F.. Açai (Euterpe oleracea Mart.) feeding attenuates dimethylhydrazine-induced rat colon carcinogenesis. Food and Chemical Toxicology, 58, 68-76 (2013).

Gai, Q.Y.; Jiao, J.; Mu, P.S.; Wang, W.; Luo, M.; Li, C.Y; Zu, Y.G.; Wei, F.Y.; Fu, Y.J.. Microwaveassisted aqueous enzymatic extraction of oil from Isatis indigotica seeds and its evaluation of physicochemical properties, fatty acid compositions and antioxidant activities. Industrial Crops and Products, 45, 303-311 (2013).

Heinrich. M.; Dhanji, T.; Casselman, I.. Açai (Euterpe oleracea Mart.) - A phytochemical and pharmacological assessment of the species' health claims. Phytochemistry Letters, 4, 10-21 (2011).

Hogan, S.; Chung, H.; Zhang, L.; Li, J.; Lee, Y.; Dai, Y.; Zhou, K.. Antiproliferative and antioxidant properties of anthocyanin-rich extract from açai. Food Chemistry, 118, 208-214 (2010).

Jiao, J.; Li, Z.G.; Gai, Q.Y.; Li, X.J.; Wei, F.Y.; Fu, Y.J.; Ma, W.. Microwave-assisted aqueous enzymatic extraction of oil from pumpkin seeds and evaluation of its physicochemical properties, fatty acid compositions and antioxidant activities. Food Chemistry, 147, 17-24 (2014).

Latif, S. and Anwar, F.. Aqueous enzymatic sesame oil and protein extraction. Food Chemistry, 125, 679-684 (2011).

Latif, S.; Anwar, F.J.. Effect of aqueous enzymatic processes on sunflower oil quality. Journal of the American Oil Chemists' Society, 86, 393-400 (2009).

Latif, S.; Diosady, L.L.; Anwar, F.. Enzyme-assisted aqueous extraction of oil and protein from canola (Brassica napus L.) seeds. European Journal of Lipid Science and Technology, 110, 887-892 (2008).

Liu, R.H.. Dietary bioactive compounds and their health implications. Journal of Food Science, 78, 18-25 (2013).

Lopes, E.. Estudo morfoanatômico do pericarpo dos frutos de Euterpe oleracea com e sem ação de complexos enzimáticos. Master thesis. Universidade Federal do Pará. Brasil (2015).

Lubrano, C.; Robin, J.R.; Khaiat, A.. Fatty acids, sterol and tocopherol composition of oil from the fruit mesocarp of six palm species in French Guiana. Oléagineux, 49(2), 59-65 (1994). 
Machado, F.; Kuo, J.; Wohlenberg, M.F.; da Rocha Frusciante, M.; Freitas, M.; Oliveira, A.S.; Andrade, R.B.; Wannmacher, C.M.; Dani, C.; Funchal, C.. Subchronic treatment with açai frozen pulp prevents the brain oxidative damage in rats with acute liver failure. Metabolic Brain Disease, 31(6), 1427-1434 (2016).

Mai, H.C.; Truong, V.; Debaste, F.. Optimization of enzyme-aided extraction of oil rich in carotenoids from gac fruit (Momordica cochinchinensis Spreng). Food Technology and Biotechnology, 51(4), 488-499 (2013).

Maistro, E.L.; Marques, E.S.; Tsuboy, M.S.F.. Cytotoxic and genotoxic assessment of Euterpe oleracea fruit oil and Pentaclethra macroloba oil in human peripheral lymphocytes. Toxicology Letters, 221(28), 126 (2013).

Marques, E.S.; Froder, J.G.; Carvalho, J.C.T.; Rosa, P.C.P.; Perazzo, F.F.; Maistro, E.L.. Evaluation of the genotoxicity of Euterpe oleraceae Mart. (Arecaceae) fruit oil (açai), in mammalian cells in vivo. Food and Chemical Toxicology, 93, 13-19 (2016).

Marques, E.S.; Tsuboy, M.S.F.; Carvalho, J.C.T.; Rosa, P.C.P.; Perazzo, F.F.; Gaivão, I.O.M.; Maistro, E.L.. First cytotoxic, genotoxic, and antigenotoxic assessment of Euterpe oleracea fruit oil (açai) in cultured human cells. Genetics and Molecular Research, 16(3), 1-11 (2017).

Monge-Fuentes, V.; Muehlmann, L.A.; Longo, J.P.; Silva, J.R.; Fascineli, M.L.; de Souza, P.; Faria, F.; Degterev, I.A.; Rodriguez, A.; Carneiro, F.P.; Lucci, C.M.; Escobar, P.; Amorim, R.F.; Azevedo, R.B.. Photodynamic therapy mediated by açai oil (Euterpe oleracea Martius) in nanoemulsion: A potential treatment for melanoma. Journal of Photochemistry and Photobiology B: Biology, 166, 301-310 (2017).

Moura, R.S.; Resende, A.C.. Cardiovascular and metabolic effects of açaí, an Amazon plant. Journal of Cardiovascular Pharmacology, 68(1), 19-26 (2016).

Nascimento, R.J.S.; Curi, S.; Assi, R.A.; Freitas, S.P.. Composição em ácidos graxos do óleo da polpa de açaí extraído com enzimas e com hexano. Revista Brasileira de Fruticultura, 30(2), 498-502 (2008).

Pacheco-Palencia, L.A.; Talcott, S.M.; Talcott, S.T.. Chemical composition, antioxidant properties, and thermal stability of a phytochemical enriched oil from açai (Euterpe oleracea Mart.). Journal of Agricultural and Food Chemistry, 56, 4631-4636 (2008a).

Pacheco-Palencia, L.A.; Talcott, S.T.; Safe, S.; Mertens-Talcott, S.. Absorption and biological activity of phytochemical-rich extracts from açai (Euterpe oleracea Mart.) pulp and oil in vitro. Journal of Agricultural and Food Chemistry, 56(10), 3593-3600 (2008b).
Plotkin, M.J.; Balick, M.. Medicinal uses of South American palms. Journal of Ethnopharmacology, 10, 157-179 (1984).

Poulose, S.M.; Fisher, D.R.; Larson, J.; Bielinski, D.F.; Rimando, A.M.; Carey, A.N.; Schauss, A.G.; Shukitt-Hale, B.. Anthocyanin-rich acai (Euterpe oleracea Mart.) fruit pulp fractions attenuate inflammatory stress signaling in mouse brain BV-2 microglial cells. Journal of Agricultural and Food Chemistry, 60, 1084-1093 (2012).

Poulose, S.M.; Fisher, D.R.; Bielinski, D.F.; Gomes, S.M.; Rimando, A.M.; Schauss, A.G.; ShukittHale, B.. Restoration of stressor-induced calcium dysregulation and autophagy inhibition by polyphenolics-rich acai (Euterpe spp.) fruit pulp extracts in rodent brain cells in vitro. Nutrition, 30(7), 853-862 (2014).

Poulose, S.M.; Bielinski, D.F.; Carey, A.; Schauss, A.G.; Shukitt-Hale, B.. Modulation of oxidative stress, inflammation, autophagy and expression of Nrf2 in hippocampus and frontal cortex of rats fed with açaí-enriched diets. Nutritional Neuroscience, 20(5), 265-272 (2017).

Puangsri, T.; Abdulkarim, S.M.; Ghazali, H.M.. Properties of Carica papaya 1. (papaya) seed oil following extractions using solvent and aqueous enzymatic methods. Journal of Food Lipids, 12, 62-76 (2005).

Ricochon, G.; Muniglia, L.. Influence of enzymes on the oil extraction processes in aqueous media. OCL, 17(6), 356-359 (2010).

Rosenthal, A.; Pyle, D.L.; Niranjan, K.. Aqueous and enzymatic process for edible oil extraction. Enzyme and Microbial Technology, 19, 402-420 (1996).

Rui, H.; Zhang, L.; Li, Z.; Pan,N, Y.. Extraction and characteristics of seed kernel oil from white pitaya. Journal of Food Engineering, 93, 482-486 (2009).

Schauss, A.G.; Wu, X.; Prior, R.L.; Ou, B.; Patel, D.; Huang, D.; Kababick, J.P.. Phytochemical and nutrient composition of the freeze-dried Amazonian palm berry, Euterpe oleraceae Mart. (Açai). Journal of Agricultural and Food Chemistry, 54, 8598-8603 (2006).

Schauss, A. G.. Açai (Euterpe oleracea Mart.): A macro and nutrient rich palm fruit from the Amazon rain forest with demonstrated bioactivities in vitro and in vivo. In D. R. Watson \& V. R. Preedy (Eds.), Bioactive foods promotion health (pp. 479-490). Oxford: Academic Press (2010)

Sicaire, A-G.; Vian, M.; Fine, F.; Joffre, F.; Carré, P.; Tostain, S.; Chemat, F.. Alternative bio-based solvents for extraction of fat and oils: Solubility prediction, global yield, extraction kinetics, chemical composition and cost of manufacturing. International Journal of Molecular Sciences, 16(4), 8430-8453 (2015). 
Skrovankova, S.; Sumczynski, D.; Mlcek, J.; Jurikova, T.; Sochor, J.. Bioactive compounds and antioxidant activity in different types of berries. International Journal of Molecular Sciences, 16(10), 2467324706 (2015).

Souza, M. O.; Silva, L. S.; Magalhães, C. L. B.; Figueiredo, B. B.; Costa, D. C.; Silva, M. E.; Pedrosa, M. L.. The hypocholesterolemic activity of açai (Euterpe oleracea Mart.) is mediated by the enhanced expression of ATP-binding cassette, subfamily G transporters 5 and 8 lowdensity lipoprotein receptor genes in rat. Nutrition Research, 32, 976-984 (2012).

Souza, B.S.F.; Carvalho, H.O.; Ferreira, I.M.; da Cunha, E.L.; Barros, A.S.; Taglialegna, T.; Carvalho, J.C.T.. Effect of the treatment with Euterpe oleracea Mart. oil in rats with Triton-induced dyslipidemia. Biomedicine \& Pharmacotherapy, 90, 542-547 (2017).

Tabtabaei, S. and Diosady, L.L.. Aqueous and enzymatic extraction processes for the production of food-grade proteins and industrial oil from dehulled yellow mustard flour. Journal of Food Research International, 52, 547-556 (2013).

Xie, C.; Kang, J.; Burris, R.; Ferguson, M.E.; Schauss, A.G.; Nagarajan, S.; Wu, X.. Açai juice attenuates atherosclerosis in ApoE deficient mice through antioxidant and anti-inflammatory activities. Atherosclerosis, 216, 327-333 (2011).

Yamaguchi, K.K.L.; Pereira, L.F.R; Lamarão, C.V.; Lima, E.S.; Veiga-Junior, V.F.. Amazon acai: Chemistry and biological activities: A review. Food Chemistry, 179, 137-151 (2015).

Yusoff, M.M.; Gordon, M.H.; Niranjan, K.. Aqueous enzyme assisted oil extraction from oilseeds and emulsion de-emulsifying methods: A review. Trends in Food Science \& Technology, 41, 60-82 (2015).

Zhang, S.; Wang, Z.; Xu, S.Y.. Optimization of the aqueous enzymatic extraction of rapeseed oil and protein hydrolysates. Journal of the American Oil Chemists' Society, 84, 97-105 (2007). 
